\title{
The National Secretariat GEOSS/GMES - Implementation of GEOSS and GMES in the Czech Republic
}

\author{
Jaromír Adamuška ${ }^{1}$ and Simona Losmanová \\ ${ }^{1}$ Ministry of the Environment of the Czech Republic, Vršovická 65, Prague 10, \\ 100 10, Czech Republic \\ jaromir.adamuska@mzp.cz \\ ${ }^{2}$ CENIA, Czech Environmental Information Agency, Litevská 8, Prague 10, \\ 100 05, Czech Republic \\ simona. losmanova@cenia.cz
}

\begin{abstract}
The aim of the article is to present the role and activities of the National Secretariat GEOSS/GMES (NS). Existence of the NS was declared by the Czech Governmental Resolution No. 229/2009. This resolution requires activities of two ministries - the Ministry of the Environment and the Ministry of Education, Youth and Sports to coordinate Czech activities related to international programmes GEOSS and GMES. The goal of GEOSS and GMES is building up an integrated and sustainable system by sharing and providing information services on the environment, especially those based on Earth observation and remote sensing technologies. The article explains the Czech approach to the coordination of GEOSS/GMES. The coordination is necessary for efficient exploitation of the first-emerged services and also for expanding information to the user's community. The NS Work Plan 2011 was introduced at the beginning of this year and some goals have already been achieved.
\end{abstract}

Keywords: GMES, GEOSS, GEO, European Commission, National Secretariat, environment, data, users, services, coordination, remote sensing.

\section{Introduction}

The Czech Republic is actively participating in the European programme Global Monitoring for Environment and Security (GMES) by expanding awareness about GMES at the national level through the implementation of developing knowledge and best practices into a governmental management system in the Czech Republic. GMES is often presented as the second pillar of the EU space policy after the Galileo programme. However, GMES is not only related to space. The GMES programme consists of three elements: the space component, the in-situ component and services driven by the user's needs.

There are many definitions of GMES. All of them reflect the original idea from the Baveno Manifesto in 1998. Some parts of GMES can be emphasized by different interest groups. Maybe the most accurate description of GMES is the one which says that GMES is a framework for sustainable, standardized and operational services used for efficient management of environmental, ecological and social threats. Moreover, different approaches to GMES increase the importance of this programme as the EU 
contribution to the worldwide GEOSS (Global Observation System of Systems) initiative developed by The Group on Earth Observation (GEO).

After more than 12 years of continuous effort, GMES finally advanced to the preoperational phase. The most important milestone was the issuing of Regulation No. 911/2010 [1], which entered into force on 9 November 2010. This regulation shifted GMES from an initiative to a programme or, in other words, to the stage when GMES gained its own budget, and also enforced its relevance and importance. Not surprisingly, an increase of claims and a growth of the agenda concerning the coordination between the EU and Member States is anticipated. The key aspect is a usage of the maximum potential that this programme brings. Each Member state has a different approach how to tackle this issue. This article describes the Czech approach to the coordination of GMES activities within the Czech Republic.

\section{Czech Approach to GMES}

The Czech Republic has been increasing its involvement in the European programme Global Monitoring for Environment and Security (GMES) by different actions since November 2010 in order to be very well-prepared for the year 2014 when GMES should be fully operational. The first step of the Czech Republic's involvement within the GMES initiative emerged at the end of 2006. At that time, the Czech government approved the engagement of the Czech Republic with GEO and agreed to the building up of the integrated and sustained GEOSS, as well as agreed with its participation in GMES. The competence for the coordination and carrying out of these issues has been given to two ministries: the Ministry of the Environment (MoE) and the Ministry of Education, Youth and Sports (MoEYS). The MoE includes those connected with the environment - major users or potential data producers (or service providers). The MoEYS represents the research sector - institutions which are able to participate in the developing and the designing of services and associated technologies. In 2006, GMES was in its early stage and had the status of an initiative. Particular projects were exclusively funded from the EU Framework programme (FP6 and later from FP7). The first aim of those projects was to develop pilot services based on existing data sources to prove potential and possibilities, need and usage of GMES. After finishing these projects, it was necessary to maintain the vital built-up services (Framework Programmes for R\&D do not intend to operate project outputs). To cope with this issue was crucial and it was due to one of these mentioned cases which led to the preparation of the new legislation to underpin GMES.

This context was also reflected at the national level. The priority was to set up an organizational framework for the coordination of GMES activities within the Czech Republic and to ensure the consultation of prepared EU legislation between 2007 and 2010. It proceeded through both ministries which were involved at the national level as well as through Czech delegates from the GMES Advisory Council of the EU. In relation to the increasing need for better GMES coordination, the Czech government authorized the MoE and the MoEYS in spring 2009 to establish the National Secretariat of GEOSS/GMES (NS) as an operational body to deal with GMES and GEOSS issues. This particularly gave power to the NS to regulate and advise public institutions for the purchasing of remote sensing data. The NS was established in July 2010 and has been in full operation since November 2010. The NS consists of four members from the most relevant institutions coming under both ministries: a secretary from the MoE who 
is responsible for official communication within national authorities and two GMES specialists - the first one represents CENIA, Czech Environmental Information Agency; focusing on user's needs, community and overlaps to INSPIRE and SEIS. The second specialist comes from the Czech Space Office and he specialises in the research aspects of GMES and the funding of projects through the EU Framework Programme. The fourth member of the NS is a representative of the Czech Hydrometeorological Institute covering GEOSS, atmosphere, hydrology, climate and meteorology.

The first completed goal of the NS was to launch the Czech portal (www.gmes.cz) at the end of 2010. This portal provides comprehensive information about GMES and GEO activities in a bilingual version - Czech and English. Visitors may find here useful information about the evolution of GMES and GEOSS along with the structure scheme of the NS. Services like downloading documents, signing for newsletters or asking questions are offered via the e-mail address: info@gmes.cz. A calendar with interesting events such as project calls, conferences, seminars and workshops is

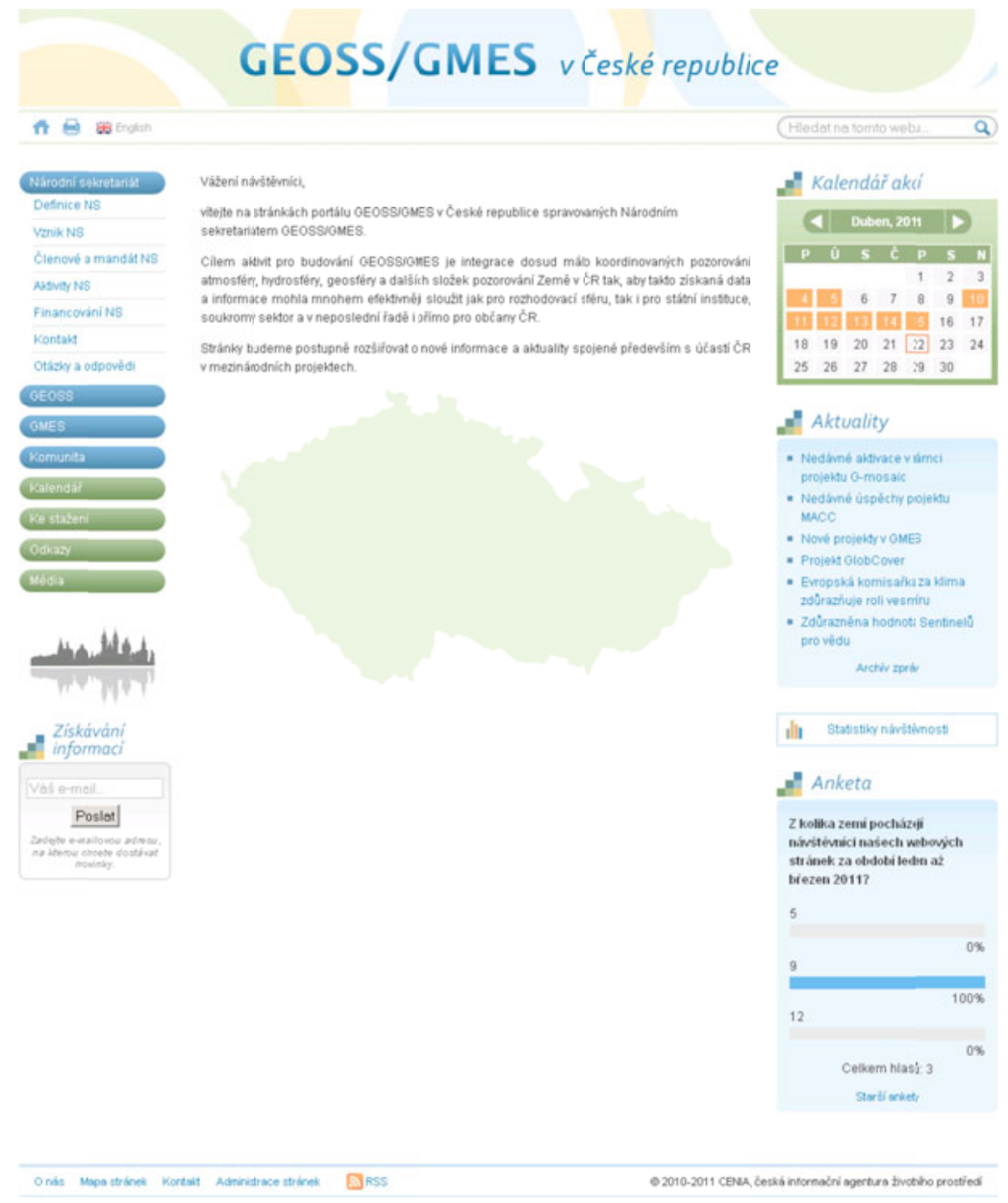

Fig. 1. The Czech portal www.gmes.cz 
updated regularly together with news section [2]. Another step was the completion of the document called "Strategy of the Implementation of GEOSS and GMES in the Czech Republic 2011-2013". This internal document represents a road map type plan and summarises the aims and priorities of the activities for the NS members. At the same time, the strategy presents the main principles and spheres of the NS work and specifies its particular activities.

Members of the NS represent the Czech Republic within the EU and sit within different bodies. One of them is the recently established User Forum managed by the GMES Bureau which is driven by the EU General Directorate for Enterprise and Industry (DG ENTR). The second one is the GMES Committee (GC). In fact, the Czech Republic is represented at the GC's meetings by two delegates independently nominated by the MoE instead of the NS's members. In spite of this, they closely and independently cooperate with the NS (consultation of voting instructions, etc.). The NS can also cover delegate's participation if the need arises. Currently the NS is helping to find the best suitable candidate for the Security Board.

There is also an active cooperation with the Ministry of Transport and the Ministry of Interior as an example of interaction on the highest institutional level. The communication with other relevant public authorities is secured by the Coordination Board of GEOSS/GMES (CB). The CB, consisting of various public representatives, shall collect GEOSS/GMES positions and needs of other resorts. The CB recommendations help the Ministry of the Environment to specify main NS's forehead activities.

\section{Conclusion}

Considering the tight time frame, the National Secretariat of GEOSS/GMES (NS) has achieved a lot. The necessity for the coordination procedures connected with remote sensing data is undisputable. The NS was established not only as the advisory body and as the coordinator, but was also created for saving national expenditures. Therefore, the NS will be the main contact point for relevant public institutions to discuss their needs. The NS will provide them with correct information about available remote sensing data and opportunities to engage themselves with GMES projects. It is very important to highlight the fact that remote sensing data coming from the EU to Member States should be free for public authorities. The NS will provide information about GMES and GEOSS through different types of media (internet website, oral presentations, leaflets). The NS will motivate experts from research or academic institutions and also support SMEs to benefit from GMES. The NS will also ensure consultation of the EUs strategic and legislative materials. Overall, the NS will help the Czech Republic to eliminate or to reduce information gaps by close cooperation among institutions.

Future advantages will depend on the quality of cooperation among all parties involved.

\section{References}

1. Regulation of the European Parliament and of the Council of 22 September 2010 on the European Earth monitoring programme (GMES) and its initial operations (2011-13), http://ec.europa.eu/enterprise/policies/space/files/gmes/ regulation_\%28eu\%29_no_911_2010_en.pdf

2. GEOSS/GMES in the Czech Republic, http://www.gmes.cz/en 